This item was submitted to Loughborough's Research Repository by the author.

Items in Figshare are protected by copyright, with all rights reserved, unless otherwise indicated.

\title{
Kinematic parameters contributing to the production of spin in elite finger spin bowling
}

\section{PLEASE CITE THE PUBLISHED VERSION}

https://doi.org/10.1080/02640414.2018.1474531

\section{PUBLISHER}

(C) Taylor \& Francis

\section{VERSION}

AM (Accepted Manuscript)

\section{PUBLISHER STATEMENT}

This is an Accepted Manuscript of an article published by Taylor \& Francis in Journal of Sports Sciences on 9 May 2018, available online: http://www.tandfonline.com/10.1080/02640414.2018.1474531.

\section{LICENCE}

CC BY-NC-ND 4.0

\section{REPOSITORY RECORD}

Sanders, L., Paul Felton, and Mark King. 2019. "Kinematic Parameters Contributing to the Production of Spin in Elite Finger Spin Bowling”. figshare. https://hdl.handle.net/2134/33129. 


\title{
Kinematic parameters contributing to the production of spin in elite finger spin bowling
}

\author{
${ }^{1}$ L. Sanders, ${ }^{1}$ P.J. Felton and ${ }^{1}$ M.A. King. \\ ${ }^{1}$ School of Sport, Exercise and Health Sciences, Loughborough University, Leicestershire, LE11 3TU, UK
}

\begin{abstract}
The aim of this study was to identify the key kinematic parameters which contribute to higher spin rates in elite finger spin bowling. Kinematic data were collected for twentythree elite male finger spin bowlers with thirty kinematic parameters calculated for each delivery. Stepwise linear regression and Pearson product moment correlations were used to identify kinematic parameters linked to spin rate. Pelvis orientation at front foot contact $(r=0.674, p<0.001)$ and ball release $(r=0.676, p<0.001)$ were found to be the biggest predictors of spin rate, with both individually predicting $43 \%$ of the observed variance in spin rate. Other kinematic parameters correlated with spin rate included: shoulder orientation at ball release $(r=0.462, p=0.027)$, and pelvis-shoulder separation angle at front foot contact $(r=0.521, p=0.011)$. The bowlers with the highest spin rates adopted a mid-way pelvis orientation angle, a larger pelvis-shoulder separation angle and a shoulder orientation short of side-on at front foot contact. The segments then rotated sequentially, starting with the pelvis and finishing with the pronation of the forearm. This knowledge can be translated to coaches to provide a better understanding of finger spin bowling technique.
\end{abstract}

Keywords: cricket, finger spin bowling, spin rate, linear regression

\section{INTRODUCTION}

In cricket, successful spin bowlers attempt to deviate the ball in the air (either horizontally and/or vertically due to the Magnus force (Sayers and Hill, 1999)) and off the pitch in an attempt to deceive the opposing batter (Woolmer and Noakes, 2008). The amount of spin is considered a major contributor to spin bowling success with elite finger spin bowlers having been shown by Chin et al. (2009) to deliver the ball with more spin than their sub-elite counterparts (1602 \pm 276 vs. $1332 \pm 228 \mathrm{rpm}$ ). Relatively few investigations have sought to identify the aspects of finger spin bowling technique that are linked to spin rate and how these aspects of technique may interact with one another, in an attempt to understand how certain bowlers are able to release the ball with higher spin rates than others. This scarcity of finger spin bowling research has resulted in the coaching and talent identification of spin bowlers to be based on anecdotal evidence (Feros et al., 2017).

Coaching literature suggests that the optimal technique for finger spin bowling is one where the pelvis and shoulders rotate from a side-on position during the delivery stride, to front-on at ball release (Woolmer and Noakes, 2008). It is believed that in order to optimise this movement and complete the closed kinetic chain (Newman, 2010), the pelvis should be rotated about a braced front leg by driving the rear thigh forwards (Brayshaw, 1978; Woolmer and Noakes, 2008). The movement of the bowling arm is also highlighted as important in the production of spin on the ball with particular focus on the rotations of the forearm and wrist (Woolmer and Noakes, 2008).

Previous biomechanical investigations into the technique parameters associated with higher spin rates are limited. Although Freestone et al. (2007) highlighted the importance of experience on throwing performance, the first investigation by Chin et al. (2009) sought to identify the kinematic differences been 
elite and sub-elite (high performance) finger spin bowlers in an attempt to quantify which technique parameters were key to imparting spin on the ball. They found that the six elite (international) bowlers were more side-on at back foot impact and had larger pelvis and shoulder rotations between back foot contact and ball release than their sub-elite counterparts. Elbow extension was also shown to differ between the groups of bowlers with the elite bowlers exhibiting more elbow extension than the sub-elite. Forearm pronation and wrist flexion although not significantly different were concluded to also contribute to higher spin rates and ball speeds between the two groups.

The second investigation by Beach et al. (2017) using club level bowlers linked sequencing kinematics (velocities and temporal occurrence) with spin rate using a correlation analysis and a generalised linear model. Spin bowlers were found to generally adhere to a proximal to distal sequence with the segmental motion progressing from the pelvis to the trunk and then the bowling arm. In addition, maximum rear hip flexion velocity was significantly correlated to spin rate and this provided evidence to support the anecdotal coaching literature which suggests that the kinematics of the back leg contributes to rotating the pelvis around the longitudinal axis of a braced front leg. There was no evidence however to suggest that the knee should be kept braced. Finally, examining the movement of the bowling arm, they discovered that maximum internal shoulder rotation velocity correlated to spin rate. This was deemed to be similar to other throwing movements where long-axis rotation of the upper-arm contributes to end-effector speed (Marshall and Elliott, 2000).

Although these two investigations have addressed the question of which aspects of finger spin bowling technique determine the amount of spin with which the ball is released, it is not clear whether this is the case for elite finger spin bowlers. The aim of the current study was to identify the key kinematic parameters of an elite spin bowler's technique which can predict spin rate.

\section{METHODS}

\section{Data Collection}

Twenty-three elite male finger spin bowlers (mean \pm SD: age $22.0 \pm 4.6$ years; height $1.80 \pm 0.62 \mathrm{~m}$; body mass $78.0 \pm 10.9 \mathrm{~kg}$ ) participated in the study. All bowlers were identified as "elite finger spin bowlers" by the England and Wales Cricket Board (ECB) spin bowling national coach. Each bowler was either a member of the England men's senior, A or U19 cricket team, or a current professional first class county player and identified by the ECB spin bowling national coach as having the potential to play international cricket within the next 5 years. All bowlers were deemed fit to bowl by their County or National Team Physiotherapist. The testing procedures were explained to each bowler and informed consent was obtained in accordance with the guidelines of the Loughborough University Ethical Advisory Committee. All bowlers conducted a thorough self-selected warm-up before data collection.

Fifty-six $14 \mathrm{~mm}$ retro-reflective markers were attached to each bowler positioned over bony landmarks. Ten maximal spin rate deliveries of a good length were recorded using an 18 camera (MX13) Vicon Motion Analysis System (OMG PIc, Oxford, UK) operating at $300 \mathrm{~Hz}$ on a standard length indoor artificial cricket pitch, where bowlers were able to use their full run-up. A static trial was performed for each bowler allowing body segment lengths and a neutral spine position to be calculated (Ranson et al., 2008). Ninety-five anthropometric measurements were 
also taken enabling subject-specific segmental inertia parameters to be determined for each bowler using the mathematical model of Yeadon (1990). Spin rate was recorded using the Doppler radar system, Trackman (Trackman A/S, Denmark).

\section{Data processing}

Three bowling trials for each bowler (maximum spin rate deliveries with minimal marker loss) were manually labelled and processed within Vicon's software (OMG Plc, Oxford, UK). The marker trajectories were then filtered using a recursive fourthorder low-pass Butterworth filter with a cut-off frequency of $30 \mathrm{~Hz}$ (determined using the Residual Analysis methodology described by Winter, 1990). The key instants of back foot contact (BFC), front foot contact (FFC), ball release (BR) and follow through (FT) were identified using the motions of the markers throughout the action. BFC was defined as the first frame in which the back foot's motion was visually observed to change due to contact with the ground during the delivery stride. Similarly, FFC corresponded to the first frame that the front foot contacted with the ground during the delivery stride and FT corresponded to the foot contact after FFC. BR was identified using the time history of the distance between the ball and the wrist joint centre. The frame corresponding to ball release was defined as the first frame in which this distance increased by more than $20 \mathrm{~mm}$ relative to the distance in the previous image (Worthington et al., 2013).

Three-dimensional joint centre time histories for the ankle, knee, shoulder, elbow, and wrist joint centres were calculated from the pair of markers placed across each joint, positioned such that their midpoint coincided with the joint centre (Worthington et al., 2013). The hip joint centre time histories were calculated from markers placed over the left and right anterior superior iliac spine and the left and right posterior superior iliac spine (Davis et al., 1991). The endpoints of the lower and upper trunk segments were defined using the four markers on the pelvis in addition to markers placed over the cephalad and caudad ends of the sternum as well as the spinous processes of L1, T10 and C7 (Roosen and Pain, 2007).

Local reference frames were defined comprising a three-dimensional full-body 18-segment representation of a bowler (head and neck; upper trunk; lower trunk; pelvis; $2 \times$ arm; $2 \times$ lower-arm; $2 \times$ hand; $2 \times$ upper-leg $2 \times$ lower-leg; and $2 \times$ twosegment foot). Reference frames were defined using three markers on the segment itself, allowing segment orientations and joint angles to be calculated. The z-axis pointed upwards along the longitudinal axis of the segment, the $x$-axis pointed toward the bowler's right with the y-axis pointing forward. Similarly, a global coordinate system was defined with the y-axis pointing down the wicket, toward the batsman, the $x$-axis pointing to the right and the z-axis representing the upwards vertical. Joint angles were calculated as Cardan angles, defined as a parent-child coordinate system. This defines the rotation applied to the parent coordinate system (proximal segment) to bring it into coincidence with the coordinate system of the child segment (distal segment). Rotation angles were calculated using an xyz sequence, corresponding to flexion-extension, abduction-adduction, and longitudinal rotation, respectively (Worthington et al., 2013).

Run-up velocity (in the global y-direction) was calculated as the mean mass centre velocity over a period of 18 frames $(0.060 \mathrm{~s})$ immediately before the instant of BFC and the orientation of the shoulders and pelvis were calculated by projecting their respective joint centres onto the transverse plane (Worthington et al., 2013). All orientations for both left and right handed bowlers were expressed using definitions based on a right handed bowler. A bowler facing directly down the wicket (front-on) 
was defined to have a shoulder and pelvis orientation angle of $270^{\circ}$, a side-on position corresponded to an orientation angle of $180^{\circ}$ (Figure 1). The pelvis-shoulder separation angle was calculated by subtracting the pelvis orientation angle from the shoulder orientation angle. The orientations of the front and back foot were also calculated in the transverse plane. A foot pointing directly down the wicket was defined to have a foot orientation angle of $360^{\circ}$, and a foot position parallel to the stumps corresponded to an orientation angle of $270^{\circ}$ (Figure 1 ).

(a)

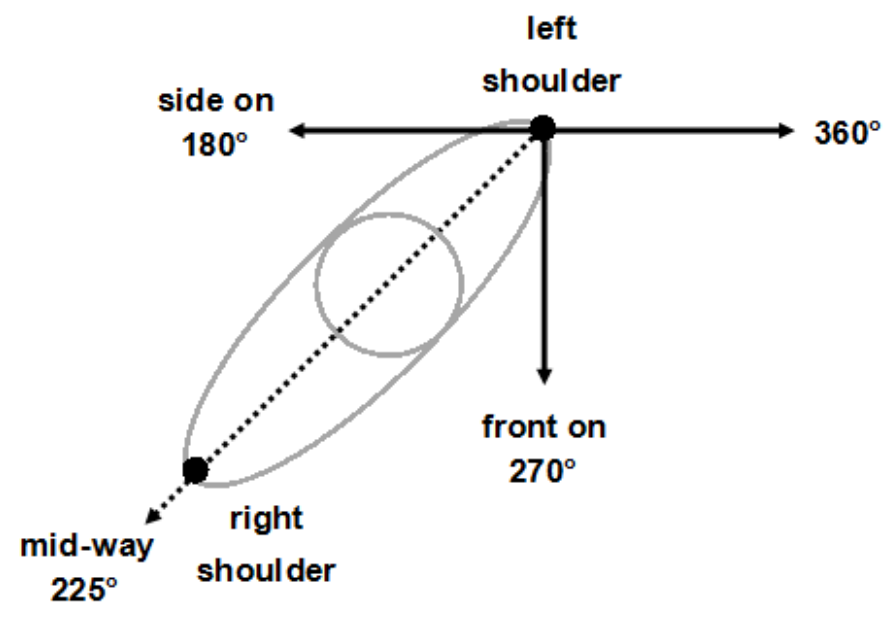

(b)

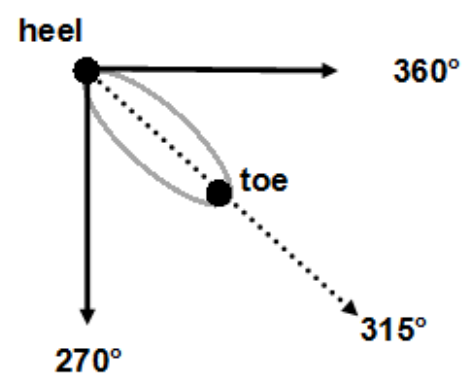

bowling direction

Figure 1. (a) shoulder and pelvis orientation angles in the transverse plane, (b) foot orientation angles in the transverse plane.

\section{Data Analysis}

Thirty kinematic parameters were determined for each bowling trial, defining key kinematic aspects of spin bowling technique:

- $\quad$ run-up velocity

- back foot orientation at BFC

- front foot orientation at FFC and BR

- $\quad$ front foot rotation from BR to FT

- $\quad$ pelvis orientation at BFC, FFC, BR and FT

- $\quad$ minimum pelvis orientation from $B F C$ to $B R$

- $\quad$ pelvis rotation from BFC to BR and from BFC to FT

- $\quad$ shoulder orientation at BFC, FFC, BR and FT

- $\quad$ minimum shoulder orientation from BFC to BR

- $\quad$ shoulder rotation from BFC to BR and from BFC to FT

- $\quad$ pelvis-shoulder separation at BFC, FFC, and BR

- trunk flexion from FFC to BR

- $\quad$ elbow extension from upper arm horizontal (UAH) to BR

- front knee extension from FFC to BR

- front hip internal rotation from FFC to BR

- $\quad$ trunk rotation from FFC to BR 
- $\quad$ shoulder internal rotation from FFC to BR

- $\quad$ forearm pronation from FFC to BR

- $\quad$ wrist flexion from FFC to BR

All statistical analyses were performed within SPSS v.23 (SPSS Corporation, USA). The variation observed in each technique parameter calculated (including spin rate) was assessed using an analysis of variance (ANOVA). The between-trial variability was compared with the between-bowler variability and was found to be much smaller. In particular, the between-trial standard deviations of the observations ranged from $1.2 \%$ to $18.0 \%$ (mean: $4.7 \%$ ) of the between-bowler variation for the parameters calculated in this study. This corresponded to an intra-class correlation coefficient (ICC) of 0.91-0.99 (mean: 0.98) which indicates good between-trial repeatability for the kinematic parameters calculated. Consequently, the three trials analysed were averaged for each parameter to provide representative data for each bowler (Worthington et al., 2013).

Correlations between each kinematic (independent) variables and ball spin rate (dependent variable) were assessed using Pearson product moment correlation analyses. An alpha value of 0.05 was used to determine significance; however, due to the exploratory nature of the study, variables with alpha values up to 0.1 were noted in the Results and Discussion.

To identify the key kinematic parameters which best explain the variation in spin rate, the parameters which were significantly correlated to spin rate were entered as "candidate" variables in a forwards stepwise linear regression model. The entry requirement for the inclusion of a parameter into the regression equation was $\mathrm{P}<$ 0.05 with a removal coefficient of $P>0.10$. Similarly, the regression model was rejected if the coefficient 95\% confidence intervals included zero, the residuals of the predictor were heteroscedastic or if the bivariate correlations, tolerance statistics or variance inflation factors showed any evidence of multicollinearity (Bowerman and O'Connell, 1990; Draper and Smith; 1998; Field, 2013; Menard, 1995; Myers, 1990). The normality of the standardised residuals in the regression model was also confirmed via a Shapiro-Wilk test. The percentage of variance in the dependent variable (spin rate) explained by the kinematic (independent) variables in the regression equation was determined by Wherry's (1931) adjusted $R^{2}$-value. This represents an attempt to estimate the proportion of variance that would be explained by the model had it been derived from the population (elite finger spin bowlers) from which the sample was taken. To overcome the potential limitations of stepwise regressions relying on a single best model, the explained variance for all possible regression equations with the same number of predictor variables as the stepwise solution was determined for comparison.

\section{RESULTS}

The 23 participants produced ball spin rates in the range $1432-2143 \mathrm{rpm}$ $(1685 \pm 170 \mathrm{rpm})$ along with ball release speeds $17.7-23.4 \mathrm{~m} \cdot \mathrm{s}^{-1}\left(20.4 \pm 1.3 \mathrm{~m} \cdot \mathrm{s}^{-1}\right)$. Eight of the 30 kinematic parameters (Table 1) were found to be linearly correlated with spin rate (Table 2) and put forwards as "candidate" variables for entry into the linear regression. A further four parameters were found to be correlated to spin rate with alpha values of less than 0.1 . 
Table 1. 30 kinematic (technique) parameters; range, mean, standard deviation

\begin{tabular}{|c|c|c|}
\hline kinematic parameter & range & mean $\pm \mathrm{SD}$ \\
\hline run-up velocity (m/s) & $1.4-3.7$ & $2.53 \pm 0.48$ \\
\hline back foot orientation at $\mathrm{BFC}\left({ }^{\circ}\right)$ & $261.8-325.1$ & $297.7 \pm 16.8$ \\
\hline front foot orientation at $\operatorname{FFC~}\left(^{\circ}\right)$ & $311.0-373.0$ & $336.9 \pm 17.1$ \\
\hline front foot orientation at $\mathrm{BR}\left({ }^{\circ}\right)$ & $314.3-370.8$ & $343.9 \pm 13.9$ \\
\hline front foot rotation from BR to $\mathrm{FT}\left({ }^{\circ}\right)$ & $16.0-158.5$ & $107.0 \pm 32.4$ \\
\hline pelvis orientation at $\mathrm{BFC}\left({ }^{\circ}\right)$ & $171.9-226.9$ & $199.8 \pm 14.0$ \\
\hline pelvis orientation at $\mathrm{FFC}\left({ }^{\circ}\right)$ & $175.3-226.6$ & $204.6 \pm 13.3$ \\
\hline pelvis orientation at $\mathrm{BR}\left({ }^{\circ}\right)$ & $225.0-294.6$ & $265.9 \pm 14.2$ \\
\hline pelvis orientation at $\mathrm{FT}\left({ }^{\circ}\right)$ & $307.2-375.0$ & $343.1 \pm 17.1$ \\
\hline minimum pelvis orientation from $\mathrm{BFC}$ to $\mathrm{BR}\left(^{\circ}\right)$ & $163.0-211.4$ & $185.1 \pm 13.3$ \\
\hline pelvis rotation from $\mathrm{BFC}$ to $\mathrm{BR}\left({ }^{\circ}\right)$ & $55.0-111.2$ & $80.8 \pm 14.7$ \\
\hline pelvis rotation from $\mathrm{BFC}$ to $\mathrm{FT}\left({ }^{\circ}\right)$ & $109.7-198.8$ & $158.0 \pm 23.7$ \\
\hline shoulder orientation at BFC $\left(^{\circ}\right)$ & $180.0-260.6$ & $218.0 \pm 19.3$ \\
\hline shoulder orientation at FFC $\left(^{\circ}\right)$ & $160.0-198.7$ & $183.7 \pm 9.5$ \\
\hline shoulder orientation at $\mathrm{BR}\left({ }^{\circ}\right)$ & $204.8-332.1$ & $279.4 \pm 29.6$ \\
\hline shoulder orientation at FT $\left(^{\circ}\right)$ & $314.1-387.6$ & $351.1 \pm 22.2$ \\
\hline minimum shoulder orientation from $\mathrm{BFC}$ to $\mathrm{BR}\left(^{\circ}\right)$ & $159.8-198.5$ & $181.1 \pm 9.3$ \\
\hline shoulder rotation from BFC to $\mathrm{BR}\left({ }^{\circ}\right)$ & $50.0-156.2$ & $98.5 \pm 28.5$ \\
\hline shoulder rotation from BFC to $\mathrm{FT}\left({ }^{\circ}\right)$ & $123.7-212.5$ & $171.3 \pm 23.5$ \\
\hline trunk flexion from $\mathrm{FFC}$ to $\mathrm{BR}\left({ }^{\circ}\right)$ & $10.4-55.4$ & $28.7 \pm 11.7$ \\
\hline pelvis-shoulder separation at $\mathrm{BFC}\left({ }^{\circ}\right)$ & $-34.4-8.9$ & $-18.3 \pm 13.8$ \\
\hline pelvis-shoulder separation at FFC $\left({ }^{\circ}\right)$ & $-2.4-38.2$ & $20.9 \pm 9.8$ \\
\hline pelvis-shoulder separation at $\mathrm{BR}\left({ }^{\circ}\right)$ & $-52.5-43.7$ & $-13.6 \pm 22.5$ \\
\hline elbow extension from $\mathrm{UAH}$ to $\mathrm{BR}\left({ }^{\circ}\right)$ & $0.0-10.5$ & $3.65 \pm 3.24$ \\
\hline front knee extension from FFC to $\mathrm{BR}\left(^{\circ}\right)$ & $-35.3-18.2$ & $-9.5 \pm 17.0$ \\
\hline front hip internal rotation from $\mathrm{FFC}$ to $\mathrm{BR}\left(^{\circ}\right)$ & $13.6-71.2$ & $41.2 \pm 15.1$ \\
\hline trunk rotation from FFC to $\mathrm{BR}\left({ }^{\circ}\right)$ & $0.0-21.5$ & $7.2 \pm 5.3$ \\
\hline bowling shoulder internal rotation from FFC to $\mathrm{BR}\left(^{\circ}\right)$ & $8.9-51.5$ & $20.2 \pm 9.0$ \\
\hline bowling forearm pronation from $\mathrm{FFC}$ to $\mathrm{BR}\left(^{\circ}\right)$ & $0.2-21.6$ & $11.0 \pm 6.4$ \\
\hline wrist flexion from FFC to $\mathrm{BR}\left({ }^{\circ}\right)$ & $0.2-52.2$ & $30.0 \pm 14.4$ \\
\hline
\end{tabular}


Table 2. Correlations between spin rate and the 30 kinematic (technique) parameters

\begin{tabular}{|c|c|c|c|c|}
\hline \multirow[b]{2}{*}{ kinematic parameter } & \multirow[b]{2}{*}{$r$} & \multicolumn{2}{|c|}{ confidence intervals } & \multirow[b]{2}{*}{$P$} \\
\hline & & lower bound & upper bound & \\
\hline run-up velocity (m/s) & -.155 & -.432 & .192 & .481 \\
\hline back foot orientation at BFC $\left({ }^{\circ}\right)$ & $.433 * *$ & .132 & .700 & .039 \\
\hline front foot orientation at FFC $\left({ }^{\circ}\right)$ & $.416^{* *}$ & .043 & .696 & .048 \\
\hline front foot orientation at $\mathrm{BR}\left(^{\circ}\right)$ & .336 & -.003 & .596 & .117 \\
\hline front foot rotation from BR to $\mathrm{FT}\left({ }^{\circ}\right)$ & .023 & -.346 & .377 & .918 \\
\hline pelvis orientation at $B F C\left(^{\circ}\right)$ & $.379 *$ & .087 & .644 & .075 \\
\hline pelvis orientation at FFC $\left(^{\circ}\right)$ & $.674 * *$ & .401 & .837 & $<.001$ \\
\hline pelvis orientation at $\mathrm{BR}\left({ }^{\circ}\right)$ & $.676^{* *}$ & .398 & .822 & $<.001$ \\
\hline pelvis orientation at FT $\left(^{\circ}\right)$ & .236 & -.272 & .578 & .278 \\
\hline minimum pelvis orientation from $\mathrm{BFC}$ to $\mathrm{BR}\left(^{\circ}\right)$ & $.545^{* *}$ & .137 & .790 & .007 \\
\hline pelvis rotation from $\mathrm{BFC}$ to $\mathrm{BR}\left({ }^{\circ}\right)$ & .161 & -.261 & .550 & .463 \\
\hline pelvis rotation from $\mathrm{BFC}$ to $\mathrm{FT}\left({ }^{\circ}\right)$ & -.135 & -.451 & .227 & .539 \\
\hline shoulder orientation at BFC $\left(^{\circ}\right)$ & .153 & -.327 & .510 & .485 \\
\hline shoulder orientation at $F F C\left(^{\circ}\right)$ & $.405 *$ & .124 & .635 & .055 \\
\hline shoulder orientation at $\mathrm{BR}\left({ }^{\circ}\right)$ & $.462 * *$ & .183 & .705 & .027 \\
\hline shoulder orientation at FT $\left(^{\circ}\right)$ & .293 & -.206 & .604 & .175 \\
\hline minimum shoulder orientation from BFC to $\mathrm{BR}\left({ }^{\circ}\right)$ & $.430 * *$ & .108 & .649 & .041 \\
\hline shoulder rotation from $\mathrm{BFC}$ to $\mathrm{BR}\left({ }^{\circ}\right)$ & .341 & -.003 & .652 & .111 \\
\hline shoulder rotation from BFC to $\mathrm{FT}\left({ }^{\circ}\right)$ & .113 & -.338 & .446 & .609 \\
\hline trunk flexion from $\mathrm{FFC}$ to $\mathrm{BR}\left(^{\circ}\right)$ & .229 & -.082 & .554 & .293 \\
\hline pelvis-shoulder separation at BFC $\left({ }^{\circ}\right)$ & .170 & .276 & .696 & .439 \\
\hline pelvis-shoulder separation at FFC $\left({ }^{\circ}\right)$ & $.521^{* *}$ & .138 & .720 & .011 \\
\hline pelvis-shoulder separation at $\mathrm{BR}\left({ }^{\circ}\right)$ & -.181 & -.502 & .138 & .407 \\
\hline elbow extension from $\mathrm{UAH}$ to $\mathrm{BR}\left({ }^{\circ}\right)$ & -.078 & -.393 & .296 & .722 \\
\hline front knee extension from FFC to $\mathrm{BR}\left(^{\circ}\right)$ & .156 & -.393 & .565 & .477 \\
\hline front hip internal rotation from $F F C$ to $B R\left(^{\circ}\right)$ & $.371^{*}$ & -.069 & .711 & .082 \\
\hline trunk rotation from FFC to $\mathrm{BR}\left({ }^{\circ}\right)$ & .057 &.-444 & .490 & .798 \\
\hline bowling shoulder internal rotation from FFC to $\mathrm{BR}\left(^{\circ}\right)$ & -.031 & -.414 & .329 & .887 \\
\hline bowling forearm pronation from FFC to $B R\left(^{\circ}\right)$ & $.409 *$ & -.030 & .771 & .053 \\
\hline wrist flexion from FFC to $\mathrm{BR}\left({ }^{\circ}\right)$ & -.133 & -.590 & .223 & .544 \\
\hline
\end{tabular}

** Correlation to spin rate significant at the $\mathbf{0 . 0 5}$ level, * Correlation to spin rate significant at the 0.1 level. Abbreviations: back foot contact (BFC); front foot contact (FFC); ball release (BR), follow through (FT), upper arm horizontal (UAH).

The "candidate" variables were investigated initially for multicollinearity using bivariate correlations. Since the minimum shoulder orientation from BFC to BR was significantly correlated with both minimum pelvis orientation from BFC to BR and the shoulder orientation at FFC with a Pearson's correlation coefficient greater than 0.80 it was removed as a candidate variable (Field, 2013). All other significant correlations between candidate variables were below the 0.80 threshold and therefore it was deemed appropriate to enter them into the forwards stepwise linear regression.

The best individual predictor of ball spin rate was the pelvis orientation at the instant of $\mathrm{BR}$, explaining $43.1 \%$ of the variation in ball spin rate (Table 3 , Figure $2 a$ ). 
A pelvis orientation which surpassed front-on $\left(>270^{\circ}\right)$ characterised the bowlers with the highest spin rates. There was insufficient evidence $(P>0.05)$ supporting the addition of any further variables into the regression equation (Table 2). When trying all the possible combinations of candidate variables in the regression equation a model explaining $42.9 \%$ of the variance in spin rate was found using the orientation of the pelvis at FFC as the predictor variable (Table 3, Figure $2 b$ ). This indicates, along with the strong positive correlation between the orientation of the pelvis at FFC and BR $(r=0.751 p<0.01)$, that the orientation of the pelvis throughout the finger spin bowling action was a key technique parameter to increasing spin rate within this sample of elite bowlers. No other combinations of candidate variables with significant $p$-values which could explain the variance in spin rate were found when trying all other possible combinations.

Table 3. Regression equations for spin rate $(P<0.05)$

\begin{tabular}{|c|c|c|c|c|c|c|}
\hline \multirow[b]{2}{*}{ model } & \multirow[b]{2}{*}{ kinematic parameters } & \multirow[b]{2}{*}{ coefficient } & \multicolumn{2}{|c|}{ 95\% confidence intervals } & \multirow[b]{2}{*}{$p$} & \multirow[b]{2}{*}{$\begin{array}{l}\text { percentage } \\
\text { explained }\end{array}$} \\
\hline & & & $\begin{array}{l}\text { lower } \\
\text { bound }\end{array}$ & upper bound & & \\
\hline a & pelvis orientation at $\mathrm{FFC}\left({ }^{\circ}\right)$ & 8.093 & 4.088 & 12.099 & 0.001 & $43.1 \%$ \\
\hline $\mathrm{b}$ & pelvis orientation at $\mathrm{BR}\left({ }^{\circ}\right)$ & 8.656 & 4.354 & 12.958 & 0.001 & $42.9 \%$ \\
\hline
\end{tabular}
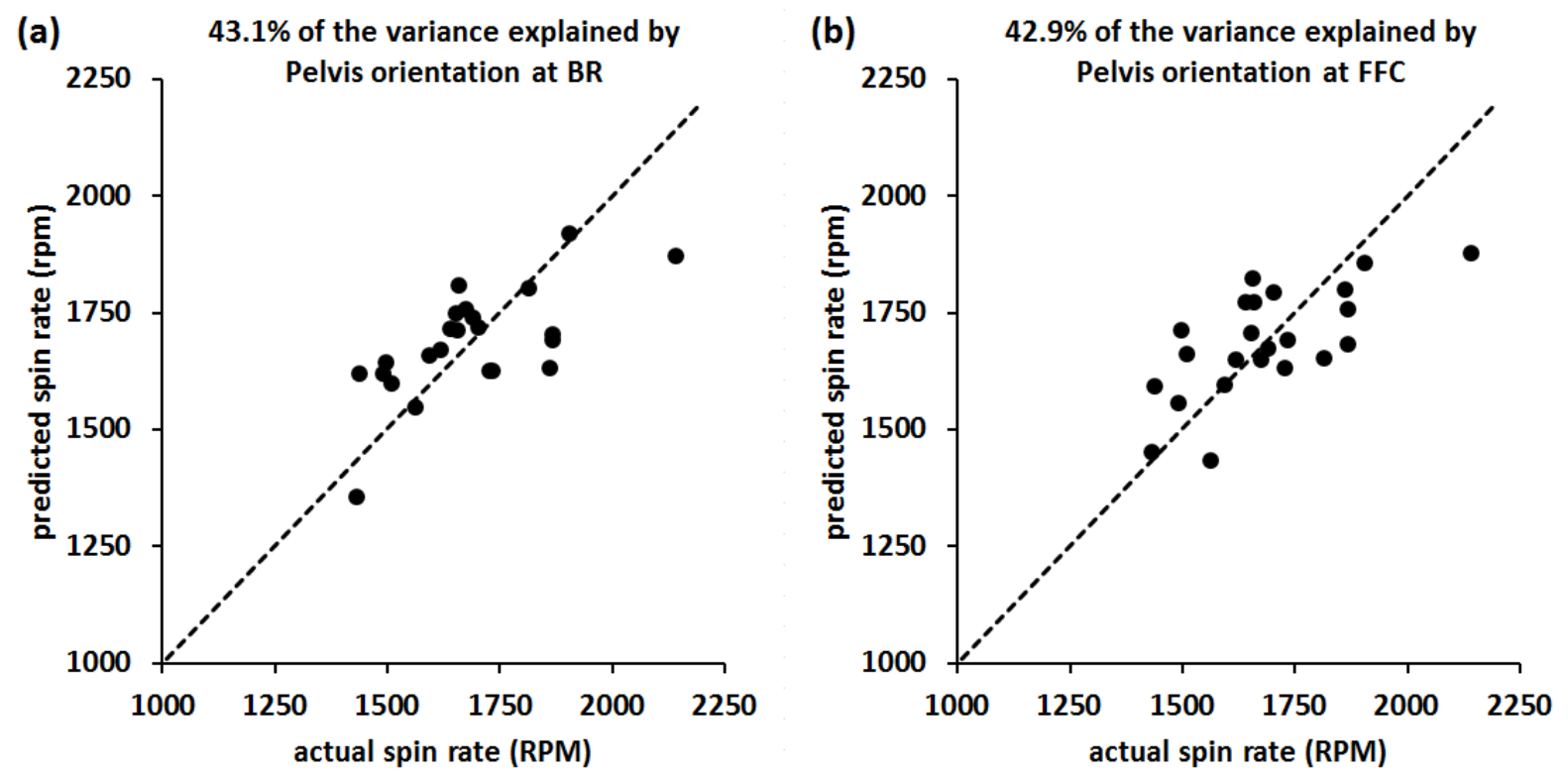

Figure 3. Predicted spin rate against actual spin rate for the two stepwise regression equations (a-b; Table 3). With a higher percentage of the variation in spin rate explained the closer the data points lie to the dashed line $y=x$ (predicted spin rate $=$ actual spin rate).

\section{DISCUSSION}

The current study aimed to investigate optimal finger spin bowling technique using correlation and regression analyses to explain the differences in spin rate among elite finger spin bowlers. The coaching literature has previously suggested that optimal technique for a finger spin bowler is one where the pelvis and shoulders rotate from a side-on position during the delivery stride, to front-on at ball release 
(Woolmer and Noakes, 2008). To achieve this the rear foot should land parallel to the popping crease with the orientation of the pelvis and hips side-on to the target. The pelvis and shoulder orientation should remain side-on at FFC. The pelvis should then be rotated about a braced front leg by driving the rear thigh forwards (Brayshaw, 1978; Woolmer and Noakes, 2008). The rotation of the shoulders should follow before finally the movements of the forearm and wrist, which are also considered of particular importance (Woolmer and Noakes, 2008). The results of this investigation, however, indicate that higher spin rates are not associated with pelvis and shoulder orientations which rotate from side-on to front-on between FFC and BR. The bowlers with the highest spin rates adopted a mid-way pelvis orientation angle, a larger pelvis-shoulder separation angle and a shoulder orientation short of side-on at FFC.

The orientation of the pelvis was shown to be the most important technique parameter with respect to increasing spin rate. The regression analysis found two models capable of explaining a very similar amount of the variance in spin rate $(42.9 \%$ and $43.1 \%)$ using the orientation of the pelvis at FFC and BR, respectively. The bowlers with the highest spin rates were found to have a pelvis orientation which was around mid-way $\left(225^{\circ}\right)$ at FFC and then rotated past front-on $\left(270^{\circ}\right)$ at ball release. The importance of the pelvis orientation throughout the delivery stride was demonstrated by positive correlations to spin rate for the minimum pelvis orientation between FFC and BR as well as the pelvis orientation at BFC. This in contrast to previously published coaching literature which recommends that the pelvis should rotate from side-on during the delivery stride to front-on at ball release (Woolmer and Noakes, 2008).

Previous research has found that the amount of pelvis rotation has been linked to higher spin rates (Chin et al., 2009). Although there were no significant correlations when calculating pelvis rotation in the transverse plane, the amount of internal hip rotation of the non-dominant limb (front hip) between FFC and BR was positively correlated to spin rate with an alpha value less than 0.1 . This suggests that those bowlers with the highest spin rates internally rotate at the hip to rotate their pelvis orientation in the transverse plane. To do this they likely drive their rear thigh forwards as has been suggested in the coaching literature (Brayshaw, 1978; Woolmer and Noakes, 2008) and by Beach et al. (2017). No evidence however has been found in this research to suggest that this rotation should occur about a braced front knee as suggested in the coaching literature (Brayshaw, 1978; Woolmer and Noakes, 2008).

Existing coaching literature recommends that the pelvis and shoulder orientations remain side-on at FFC (Woolmer and Noakes, 2008) implying there is little to no separation between them. The significant positive correlation between pelvis-shoulder separation at FFC and spin rate indicates that larger pelvis-shoulder separation angles at FFC are associated with increased spin rates which contradicts the coaching advice. Furthermore, the positive correlation between spin rate and shoulder orientation, suggests that the shoulder orientation should not be completely side-on at FFC but slightly more open (towards mid-way). It is speculated that adopting a shoulder orientation beyond side-on at FFC is likely to leave the body in a position where it is extremely difficult to complete the bowling action. The bowlers with the highest spin rates adopted a mid-way pelvis orientation angle, a larger pelvis-shoulder separation angle and a shoulder orientation short of side-on at FFC. Further investigation is required to understand the movement between BFC and FFC which allows elite spin bowlers to adopt this position. 
The significant positive correlation of spin rate with the shoulder orientation at $\mathrm{BR}$ is also in contrast to the coaching literature. The coaching literature suggests that the bowler should rotate the shoulders to face the batsman at ball release, without being completely, 'front-on' (Woolmer and Noakes, 2008). The results in this study indicate that the shoulders should rotate past front-on at BR. This contrast to the coaching literature is likely to be due to the shoulders being in a less side-on position at FFC. It is speculated however that an advantage of a shoulder orientation past front-on at BR is that this allows the arm to be in the optimal position at BR so that the motion of the arm acts towards the target.

The movements of the bowling arm and fingers have been considered of particular importance in spin bowling (Woolmer and Noakes, 2008) yet little is understood on what the optimal movement pattern is for an elite finger spin bowler. Previous research has indicated that the final components of the movement pattern in throwing and upper limb striking skills comprise of the internal rotation of the upper arm and pronation of the forearm (Marshall and Elliott, 2000). The results of this study suggest that unlike throwing or upper limb striking skills, there was no link between the internal rotation of the upper arm and spin rate. The pronation of the forearm however, was linked to higher spin rates in this sample of finger spin bowlers (Table 2). It is probable that these finger spin bowlers kept their shoulders externally rotated through to BR in order to keep the wrist and fingers on the correct side of the ball whilst maintaining a straight arm. They then pronated the forearm before and during ball release which allowed the fingers to remain in contact with the surface of the ball for longer, resulting in a larger impulse being applied, and thus increasing the amount of spin on the ball.

The positive correlations of the orientation of the back foot and front foot at initial ground contact with spin rate, suggests the feet should point more towards the target. This is expected since these orientations will allow the pelvis to adopt a more open position. This is however again in contrast with the coaching literature which advocates that the back foot should be aligned parallel to the crease (Woolmer and Noakes, 2008).

The evidence that finger spin bowlers use pelvis-shoulder separation to generate higher spin rates suggests that finger spin bowling is a movement in which the segmental rotations occur sequentially (Bartlett, 2007). This is in disagreement with the findings by Beach et al. (2017) who suggest that the segments move in a push-like movement. This study suggests that elite finger spin bowlers use a technique which maximises the separation between the pelvis and shoulders to utilise the stretch shortening cycle of the trunk and shoulder musculature similar to other throwing and upper limb striking skills.

One of the limitations of using experimental methods to investigate whether the optimal technique for an activity is correct in the coaching literature is that the techniques of the participants are likely to have been influenced by the current coaching beliefs. In order to overcome this, a large sample size is required. The sample of 23 elite finger spin bowlers is a relatively large sample of this particular population. Nevertheless, this still only resulted in one technique parameter being entered into the regression equation. Since there are many biomechanical factors between the pelvis and the ball which could influence spin rate but are not as highly correlated with spin rate as the pelvis, it was decided to comment on technique parameters from the correlations which were significant with an alpha value of 0.1 in order to identify relationships of potential interest. A further limitation of the current study is the absence of the assessment of finger motion on spin rate. In the future, 
this sample could be added to, the effect of the fingers on spin rate investigated (Karadenizli et al., 2014), or a theoretical approach be adopted to provide more insight on optimal technique to produce higher spin rates and how optimal technique might vary from bowler to bowler (Yeadon and King, 2008).

The results of this study suggest that higher spin rates can be achieved by using a finger spin bowling technique where the pelvis orientation is less side-on than previously recommended. This allows a larger pelvis-shoulder separation angle and a shoulder orientation short of side-on at FFC. During the FFC phase, the segments rotated sequentially, starting with the pelvis and finishing with the pronation of the forearm. The results of this investigation are likely to be very useful in the coaching of finger spin bowlers, as well as talent identification.

\section{ACKNOWLEDGEMENTS}

This project was part-funded by the England and Wales Cricket Board (ECB).

\section{REFERENCES}

Bartlett, R. 2007. Introduction to sports biomechanics: Analysing human movement patterns. Routledge.

Beach, A.J., Ferdinands, R.E., Sinclair, P.J. 2017. The relationship between segmental kinematics and ball spin in Type-2 cricket spin bowling. Journal of Sports Sciences, 1-8.

Bowerman, B.L., O'Connell, R.T. 1990. Linear statistical models: An applied approach. International Thomson Publishing.

Brayshaw, I. 1978. The elements of cricket. Methuen of Australia.

Chin, A., Elliott, B., Alderson, J., Lloyd, D., Foster, D. 2009. The off-break and "doosra": Kinematic variations of elite and sub-elite bowlers in creating ball spin in cricket bowling. Sports Biomechanics, 8, 187-198.

Davis, R.B., Ounpuu, S., Tyburski, D., Gage, J.R. 1991. A gait analysis data collection and reduction technique. Human Movement Science, 10, 575-587.

Draper, N.R., Smith, H. 1998. Fitting a straight line by least squares, in Applied Regression Analysis, Third Edition, John Wiley \& Sons, Inc., Hoboken, NJ, USA.

Feros, S.A., Spratford, W., Platt, N., Twomey, D.M. 2017. Cricket spin bowling remains in its biomechanical infancy. Journal of Science and Medicine in Sport. https://doi.org/10.1016/j.jsams.2017.07.011

Field, A.P. 2013. Discovering statistics using IBM SPSS statistics (4th ed.). London: Sage.

Freeston, J., Ferdinands, R. and Rooney, K., 2007. Throwing velocity and accuracy in elite and sub-elite cricket players: A descriptive study. European Journal of Sport Science, 7(4), 231-237.

Karadenizli, Z.I., Inal, H.S., Meriç, B., Aydin, M. and Bulgan, Ç., 2014. Accuracy and velocity of the elite female turkish handball players. International Journal of Sports Science, 4(1), 21-26.

Marshall, R.N, Elliott, B.C. 2000. Long-axis rotation: the missing link in proximal-todistal segmental sequencing. Journal of Sports Sciences, 18, 247-254.

Menard, S. 1995. Applied logistic regression analysis: Sage University series on quantitative applications in the social sciences. Thousand Oaks, CA: Sage. 
Myers, R. 1990. Classical and modern regression with applications (2nd ed.). Boston, MA: Duxbury.

Neuman, D.A. 2010. Kinesiology of the musculoskeletal system. Foundations for physical rehabilitation. Mosby, St.Luis.

Ranson, C.A., Burnett, A.F., King, M.A., Patel, N., O'Sullivan, P.B. 2008. The relationship between bowling action classification and three-dimensional lower trunk motion in fast bowlers in cricket. Journal of Sports Sciences, 26, 267-276.

Roosen, A., Pain, M.T.G. 2007. Kinematic changes in the reproduction of a taekwondo kicking combination. Journal of Biomechanics, 40, S455.

Sayers, A.T., Hill, A. 1999. Aerodynamics of a cricket ball. Journal of wind engineering and Industrial aerodynamics, 79, 169-182.

Woolmer, B., Noakes, T. 2008. Bob Woolmer's art and science of cricket. Struik Pub.

Worthington, P.W., King, M.A., Ranson, C. 2013. Relationships between fast bowling technique and ball release speed in cricket. Journal of Applied Biomechanics, 29, 78-84.

Wherry, R. 1931. A new formula for predicting the shrinkage of the coefficient of multiple correlation. The Annals of Mathematical Statistics, 2, 440-457.

Winter, D.A. 1990. Biomechanics and motor control of human movement. Wiley, New York.

Yeadon, M.R. 1990. The simulation of aerial movement-II. A mathematical inertia model of the human body. Journal of Biomechanics, 23, 67-74.

Yeadon, M.R., King, M.A. 2008. Computer simulation modelling in sport. In C.J. Payton and R.M. Bartlett (Eds.), Biomechanical Evaluation of Movement in Sport and Exercise: BASES Guidelines (pp. 176-205). London: Routledge. 